\title{
Diagnosis Penyakit Gigi dan Mulut Dengan Metode Forward Chaining
}

\author{
Afriosa Syawitri ${ }^{1}$, Sarjon Defit ${ }^{2}$, Gunadi Widi Nurcahyo ${ }^{3}$ \\ Jurusan Teknik Informatika, Fakultas Ilmu Komputer, Universitas Putra Indonesia YPTK Padang \\ Email: ${ }^{1}$ afriosa.syawitri27@gmail.com, ${ }^{2}$ sarjonde@yahoo.co.uk, ${ }^{3}$ gunadiwidi@yahoo.co.id,
}

\begin{abstract}
ABSTRAK
Gigi dan mulut adalah organ tubuh yang sering mengalami gangguan penyakit yang disebabkan oleh kurangnya perhatian terhadap kesehatan gigi dan mulut. Untuk mengatasi gangguan penyakit gigi dan mulut, masyarakat membutuhkan konsultasi dengan dokter spesialis guna mendapatkan hasil diagnosis terhadap penyakit yang diderita. Untuk membantu pekerjaan dokter dalam melakukan diagnosis terhadap suatu penyakit maka dibutuhkan sebuah sistem yang memiliki kemampuan dan cara berfikir seperti dokter tersebut, hal ini bisa dilakukan dengan menggunakan sistem pakar (expert system). Didalam sistem pakar membutuhkan sebuah metode salah satunya adalah metode forward chaining. Penelitian ini menghasilkan diagnosis penyakit gigi dan mulut beserta perawatan penyakit tersebut. Dengan adanya penelitian ini dapat memberikan kemudahan kepada spesialis dalam mendiagnosa penyakit gigi dan mulut. Serta dapat memudahkan pasien dalam melakukan konsultasi.
\end{abstract}

Kata Kunci: Diagnosis, gigi dan mulut, Forward Chaining

\begin{abstract}
Teeth and mouth are organs that often experience disease disorders caused by a lack of attention to dental and oral health. To overcome this dental and oral disease, the community needs consultation with a specialist to get a diagnosis of the illness. To help the doctor's work in diagnosing a disease, a system that has the ability and way of thinking like a doctor is needed, this can be done using the expert system. In expert systems requires a method one of which is the forward chaining method. This study resulted in a diagnosis of dental and oral diseases and treatment of the disease. With this research can provide convenience to specialists in diagnosing dental and oral diseases. And can facilitate patients in conducting consultations..
\end{abstract}

Keywords: Diagnosis, Teeth and mouth, Forward Chaining

Corresponding Author:

Afriosa Syawitri

Jurusan Teknik Informatika, Fakultas Ilmu Komputer

Universitas Putra Indonesia YPTK Padang

Email: afriosa.syawitri27@gmail.com

\section{Pendahuluan}

Mulut merupakan salah satu organ terpenting di dalam tubuh manusia. Mulut menjadi tempat masuknya makanan dan minuman. Di dalam mulut terdapat gigi yang berfungsi untuk menguyah makanan. Gigi dan mulut merupakan suatu kesatuan yang harus dijaga kebersihan dan kesehatannya, karena kesehatan gigi dan mulut merupakan suatu hal yang penting yang harus dijaga kebersihannya agar tidak mengalami gangguan.

Berdasarkan hasil survei kesehatan rumah tangga (SKRT) tahun 2004, sebanyak 90,05\% penduduk Indonesia mempunyai masalah kesehatan pada gigi dan mulut [1]. Beberapa faktor yang dapat menyebabkan timbulnya gangguan pada gigi dan mulut adalah kurangnya kesadaran individu untuk menjaga kesehatan rongga mulut. Pola makan juga dapat berpengaruh kepada kesehatan gigi dan mulut. Selain itu, cara menggosok gigi yang salah juga dapat menyebabkan sakit gigi, dan hal yang paling penting adalah jarangnya pemeriksaan gigi dan konsultasi secara berkala.

Terdapat banyak faktor yang menyebabkan jarangnya seseorang melakukan pemeriksaan dan konsultasi ke dokter gigi, diantaranya adalah kurangnya rasa perhatian atau kesadaran akan kesehatan gigi dan mulut, mahalnya biaya yang harus dikeluarkan untuk konsultasi, panjangnya antrian yang menyebabkan pasien kurang betah dalam menunggu.

Untuk memudahkan pasien dalam melakukan konsultasi dan memudahkan dokter dalam melakukan diagnosa awal penyakit maka dapat digunakan sebuah 
sistem yang mampu mengadopsi pengetahuan pakar atau ahli, yaitu sistem pakar. Dengan menggunakan sistem pakar dapat membantu pasien dalam konsultasi dan juga membantu dokter dalam mendiagnosa suatu penyakit. Sistem pakar adalah suatu model atau prosedur yang berkaitan, dalam suatu domain tertentu, yang mana tingkat keahliannya dapat dibandingkan dengan keahlian seorang pakar [2]. Di dalam melakukan diagnosa, sistem pakar membutuhkan sebuah metode salah satu metode itu adalah metode forward chaining.

Forward Chaining adalah metode pencarian atau teknik pelacakan ke depan yang dimulai dengan informasi atau fakta yang berupa data kemudian bergerak maju melalui premis-premis dan penggabungan rule untuk menghasilkan suatu kesimpulan (booton up reasoning) [3]. Penerapan sistem pakar dengan metode sistem pakar ini dapat diterapkan kedalam berbagai aspek, seperti sistem pakar penentuan bakat anak dengan menggunakan metode forward chaining yang dapat mengidentifikasi bakat anak [4]. Pada penelitian yang berjudul The Expert System of Children's Digestive Tract Diseases Diagnosticusing Combination of Forward Chaining and Certainty Factor Methods yang menghasilkan bahwa kombinasi antara kedua metode itu dapat mendiagnosa penyakit saluran pencernaan pada anak [5].

Pada penelitian yang berjudul System Design and Implementation Automation System of Expert System on Hydroponics Nutrients Control using Forward Chaining yang menyimpulkan bahwa dengan menggunakan metode forward chaining dapat mengambil kesimpulan tentang kondisi gizi [6]. Pada penelitian sistem pakar untuk mendeteksi kerusakan Air Conditioner menggunakan forward chaining [7].

Pada penelitian metode forward chaining untuk mendeteksi penyakit THT menghasilkan tingkat keakurasian hasil metode dengan data yang didapat dari pakar adalah sama [8]. Penelitian Expert System Applications for Early Diagnosis Teeth and Oral Disease in Children ini cukup dapat membantu dalam mengatasi masalah penyakit mulut pada anak [9]. Pada penelitian sistem pakar penyakit lambung dengan metode forward chaining mampu menganalisis gejala-gejala penyakit dan membuat diagnosa suatu penyakit dengan gejala yang ada [10].

\section{Metode Penelitian}

Metode yang digunakan dalam penelitian ini adalah forward chaining. Dimana metode Forward chaining adalah salah satu metode dalam sistem pakar. Sistem Pakar merupakan cabang dari Artificial Intelligence (AI) yang membuat ekstensi untuk spesialisasi pengetahuan guna memecahkan suatu permasalahan pada Human Expert. Human Expert merupakan seorang ahli dalam suatu bidang ilmu pengetahuan tertentu, berarti expert memiliki suatu permasalahan yang tidak dapat dipecahkan oleh orang lain secara efisien Sistem Pakar adalah sistem yang berusaha mengadopsi pengetahuan manusia ke komputer, agar komputer dapat menyelesaikan masalah seperti yang biasa dilakukan oleh para ahli. Dari pengertian di atas dapat disimpulkan bahwa Sistem Pakar adalah sistem yang mengadopsi pengetahuan atau kecerdasan manusia ke komputer, agar komputer dapat menyelesaikan masalah yang biasa dilakukan oleh manusia.

Dengan memanfaatkan Sistem Pakar ini, seseorang yang awam di suatu bidangpun dapat menyelesaikan masalah yang cukup rumit yang sebenarnya hanya dapat diselesaikan dengan bantuan para ahli. suatu teknik pencarian data atau informasi yang dimulai dengan fakta-fakta yang ada sehingga menghasilkan kesimpulan atau fakta baru.

Metode forward chaining ini sangat baik untuk digunakan jika bekerja dimulai dengan rekaman informasi awal dan ingin mencapai penyelesaian atau tujuan di akhir.

Forward Chaining berarti menggunakan himpunan aturan kondisi-aksi. Dalam metode ini, data digunakan untuk menentukan aturan mana yang akan dijalankan, kemudian aturan tersebut dijalankan. Proses akan diulang sampai ditemukan suatu hasil. Metode inferensi Forward Chaining ini cocok digunakan untuk menangani masalah pengendalian (controlling) dan peramalan (prognosis). Seperti Gambar 2.

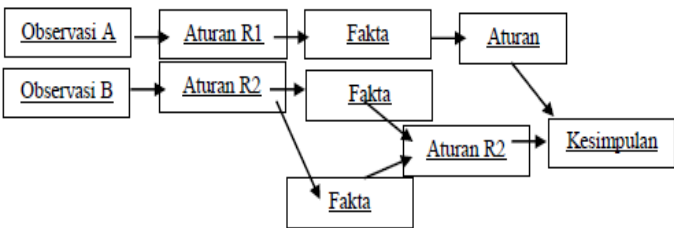

Gambar 1. Proses Forward Chaining

Dalam membuat sistem forward chaining berbasis aturan memiliki langkah-langkah yang harus dilakukan, yaitu:

a. Pendefinisian Masalah,

Pada tahap ini meliputi penilihan domain masalah dan akuisisi pengetahuan.

b. Pendefenisian Data Input

Tahap ini sistem forward chaining memerlukan data awal untuk memulai inferensi.

c. Pendefenisian Struktur Pengendalian Data

Aplikasi yang kompleks memerlukan premis tambahan untuk membantu mengendalikan pengaktifan suatu aturan.

d. Penulisan Kode Awal

Tahap ini berguna untuk menentukan apakah sistem telah menangkap domain pengetahuan secara efektif dalam struktur aturan yang baik.

e. Pengujian Sistem

Pengujian sistem dilakukan dengan beberapa aturan untuk menguji sejauh mana sistem berjalan dengan benar.

f. Perancangan Antar Muka

Antar muka adalah salah satu komponen penting dari suatu sistem. Perancangan antar muka dibuat bersama-sama dengan pembuatan basis pengetahuan.

g. Pengembangan Sistem

Pengembangan sistem meliputi penambahan antar muka dan pengetahuan sesuai dengan prototipe sistem.

h. Evaluasi Sistem 
Pada tahap ini dilakukan pengujian sistem dengan masalah yang sebenarnya. Jika sistem belum berjalan dengan baik maka akan dilakukan pengembangan kembali.

Mekanisme Inferensi dengan metode Forward Chaining dalam Sistem Pakar mempunyai tahapantahapan sederhana dalam proses penyelesaian suatu masalah menggunakan logika enkripsi dalam kaidah produksi dengan tahapan sebagai berikut:

a) Mengajukan beberapa pertanyaan kepada pengguna

b) Pertanyaan akan disimpan sebagai premis rule pada memori

c) Premis rule yang tersimpan pada memori akan di periksa atau cek kemudian menggunakan rule if then untuk memberikan kesimpulan

d) Tahap akhir adalah dengan memberikan solusi.

Untuk memberikan panduan dalam penyusunan penelitian ini maka perlu adanya susunan kerangka kerja (frame work) yang jelas tahapantahapannya, seperti Gambar 2.

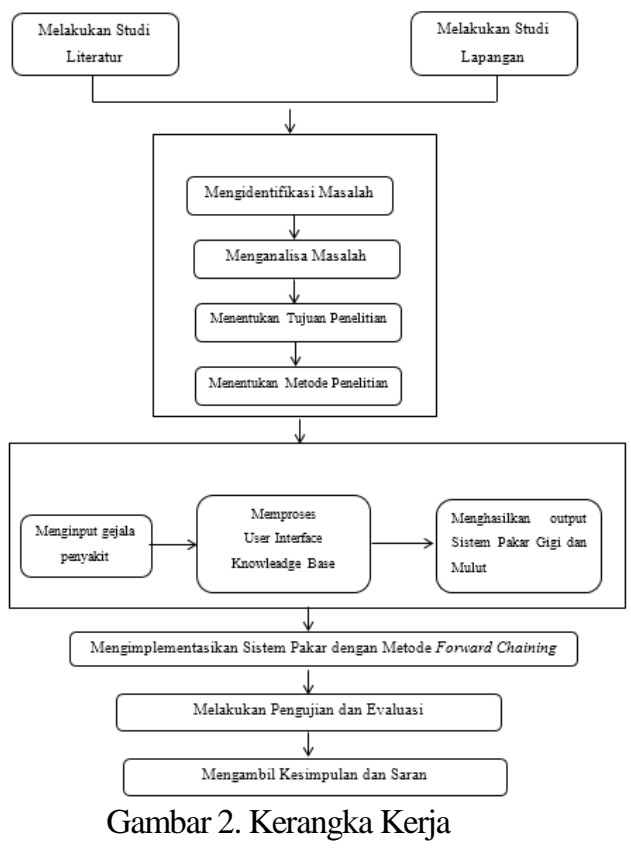

\section{Hasil dan Pembahasan}

Perancangan aturan atau rule pada Sistem Pakar diagnosa penyakit gigi dan mulut ini menggunakan metode runut maju atau forward chaining. Metode ini dipilih karena metode ini cocok diterapkan untuk mengetahui gejala-gejala penyakit gigi dan mulut. Datadata penyakit, gejala dan cara penanganan didapatkan dari wawancara langsung dengan pakar, jurnal dan bahan dari internet. Jenis penyakit gigi dan mulut ini sangat banyak, namun pada penelitian ini hanya dibahas 8 penyakit saja.

Dalam sistem pakar terdapat basis pengetahun, dimana Di dalam basis pengetahuan berisi pengetahuanpengetahuan untuk penyelesaian suatu masalah tertentu.
Basis pengetahuan ini diharapkan mampu mempunyai kemampuan mengadopsi atau menirukan pola kerja seorang ahli atau pakar. Pengetahuan (knowledge) diperoleh dari hasil wawancara dengan pakar dan hasil dari kajian literatur mengenai suatu masalah. Pengetahuan ini berupa rule-rule atau aturan-aturan untuk sistem mengambil sebuah keputusan berdasarkan kategori yang ada. Basis pengetahuan berisikan gejala dan juga penyakit tentang gigi dan mulut.

Penyakit yang menyerang gigi dan mulut beserta gejala-gejala dan penanggulangganya terdapat pada Tabel 1

Tabel 1. Penyakit Gigi dan Mulut

\begin{tabular}{|l|l|}
\hline \multicolumn{1}{|c|}{ Kode Penyakit } & \multicolumn{1}{c|}{ Nama Penyakit } \\
\hline PD01 & Gingivitis (Radang gusi) \\
\hline PD02 & Karies Gigi (gigi berlubang) \\
\hline PD03 & Karang Gigi \\
\hline PD04 & Stomatitis \\
\hline PD05 & Abses Periodental \\
\hline PD06 & Candidas Oral \\
\hline PD07 & Trench Mouth \\
\hline PD08 & Gigi Sensitif \\
\hline
\end{tabular}

Setelah jenis-jenis penyakit telah ditentukan, maka langkah selanjutnya adalah menentukan gejala-gejala dari penyakit gigi dan mulut tersebut. Tabel 2

Adapun gejala-gejala yang dimaksud terdapat pada

Tabel 2. Gejala Penyakit

\begin{tabular}{|c|l|}
\hline $\begin{array}{c}\text { Kode } \\
\text { Gejala }\end{array}$ & \multicolumn{1}{c|}{ Gejala } \\
\hline GD01 & Bau mulut \\
\hline GD02 & Gusi bengkak, merah dan berdarah \\
\hline GD03 & $\begin{array}{l}\text { Gingival berkaratin, gaung luka diantara } \\
\text { gigi dan gusi }\end{array}$ \\
\hline GD04 & $\begin{array}{l}\text { Pembesaran limfoid di kepala, leher, atau } \\
\text { rahang }\end{array}$ \\
\hline GD05 & Demam \\
\hline GD06 & Nyeri gusi \\
\hline GD07 & Sakit gigi \\
\hline GD08 & $\begin{array}{l}\text { Nyeri ringan hingga tajam saat } \\
\text { mengonsumsi makanan manis, }\end{array}$ \\
\hline GD09 & $\begin{array}{l}\text { Noda berwarna cokelat, hitam atau putih } \\
\text { pada permukaan gigi }\end{array}$ \\
\hline GD10 & Nyeri saat menggigit makanan \\
\hline GD11 & Gusi berdarah dan kemerahan \\
\hline GD12 & Gusi membengkak dan atau bernanah \\
\hline GD13 & $\begin{array}{l}\text { Gusi melorot atau gigi tampak menjadi } \\
\text { panjang }\end{array}$ \\
\hline GD14 & Gigi goyang dan sensitive \\
\hline GD15 & $\begin{array}{l}\text { Gigi menjadi meregang (timbul celah- } \\
\text { celah diantara gigi) }\end{array}$ \\
\hline GD16 & $\begin{array}{l}\text { Gigi menjadi linu padahal tidak ada yang } \\
\text { berlubang }\end{array}$ \\
\hline
\end{tabular}




\begin{tabular}{|l|l|}
\hline GD17 & Hilangnya nafsu makan \\
\hline GD18 & Terdapat luka yang cukup besar dimulut \\
\hline GD19 & $\begin{array}{l}\text { Luka biasanya terjadi beberapa kali pada } \\
\text { area yang sama }\end{array}$ \\
\hline GD20 & Luka menyebar ke bagian luar bibir \\
\hline GD21 & Tidak dapat makan dan minum \\
\hline GD22 & Rasa pahit dimulut \\
\hline GD23 & Gelisah \\
\hline GD24 & Kelelahan \\
\hline GD25 & Gusi mudah berdarah \\
\hline GD26 & $\begin{array}{l}\text { Terdapat kantung nanah yang seperti } \\
\text { benjolan dengan warna kuning }\end{array}$ \\
\hline GD27 & $\begin{array}{l}\text { Kelenjer getah bening di bawah rahang } \\
\text { membengkak }\end{array}$ \\
\hline GD28 & $\begin{array}{l}\text { Mengunyah dan menelan makanan } \\
\text { menyebabkan rasa nyeri }\end{array}$ \\
\hline GD29 & $\begin{array}{l}\text { Pecah-pecah dan kemerahan pada sudut } \\
\text { mulut }\end{array}$ \\
\hline GD30 & $\begin{array}{l}\text { Muncul bintik-bintik kuning, putih atau } \\
\text { krem di dalam mulut }\end{array}$ \\
\hline GD31 & Sedikit pendarahan apabila lesi tergores \\
\hline GD32 & Lesi menyerupai keju \\
\hline GD33 & Di dalam mulut seperti kapas \\
\hline GD34 & Kehilangan selera makan \\
\hline GD35 & $\begin{array}{l}\text { Mengunyah dan menelan makanan } \\
\text { menyebabkan rasa nyeri }\end{array}$ \\
\hline GD36 & $\begin{array}{l}\text { Ujung-ujung gusi yang terletak diantara } \\
\text { dua gigi mengalami pengikisan }\end{array}$ \\
\hline GD37 & $\begin{array}{l}\text { Rasa sakit dan tidak nyaman pada mulut } \\
\text { saat makan makanan manis atau asam }\end{array}$ \\
\hline GD38 & Rasa tidak nyaman pada saat cuaca dingin \\
\hline GD39 & Sakit pada saat menyikat gigi \\
\hline GD40 & Gusi menurun \\
\hline & \\
\hline
\end{tabular}

Langkah selanjutnya adalah menentukan rule atau aturan dengan menggunakan metode forward chaining. Perancangan aturan atau rule pada Sistem Pakar diagnosa penyakit gigi dan mulut ini menggunakan metode runut maju atau Forward Chaining. Metode ini dipilih karena metode ini cocok diterapkan untuk mengetahui gejalagejala penyakit gigi dan mulut. Berikut penyakit yang menyerang gigi dan mulut beserta gejala-gejala dan penanggulangganya.

Didalam sistem pakar terdapat Inference Engine, di mana Inference Engine merupakan komponen terpenting didalam Sistem Pakar yang berisi tentang prosedurprosedur untuk pencocokan fakta dengan aturan dan hasil, selain itu juga berisi prosedur atau langkah pertama dalam membangun inference engine. Secara dedukatif mesin inferensi memilih pengetahuan yang relevan dalam rangka mencapai kesimpulan. Dengan demikian sistem ini diharapkan mampu menjawab pertanyaan user meskipun jawaban dari pertanyaan tersebut tidak tersimpan didalam basis pengetahuan. Mesin inferensi memulai pelacakannya dengan mencocokkan kidahkaidah dalam basis pengetahuan dengan fakta-fakta yang ada dalam basis data. Selain itu, juga dapat dengan menngunakan teknin penelusuran data dalam bentuk network atau jaringan yang terdiri atas node-node berbentuk tree atau pohon.

Mesin Inference (Inference Engine) adalah bagian yang mengandung mekanisme fungsi berfikir dan pola- pola penalaran sistem yang akan menganalisis suatu masalah tertentu dan selanjutnya akan mencari jawaban atau kesimpulan yang tebaik. Secara deduksi Mesin Inferensi memilih pengetahuan yang relevan dalam rangka mencapai kesimpulan. Inference Engine merupakan bagian terpenting dari Sistem Pakar yang berperan dalam menentukan efektifitas dan efisiensi sistem. Mesin Inferensi memiliki tiga elemen pokok yaitu:

a. Penerjemah (Interpreter), yang menjalankan pilihan jenis-jenis agenda dengan menerapkan kaidah basis pengetahuan yang ada.

b. Pengaturan (Scheduler), yang mengatur control atas agenda. Penalaran mempengaruhi kaidah inferensi dalam jenis prioritas yang jelas atau kriteria lain dalam agenda.

c. Kemampuan Penyelesaian (Consistency Enforcer), yang mencoba untuk menjaga ketepatan representasi dari penyelesaian yang muncul. Bagian ini akan berusaha memelihara kekonsistenan dalam merepresentasikan solusi yang bersifat darurat.

Rule atau aturan menggunankan metode forward chaining terdapat pada Tabel 3

Tabel 3. Aturan atau Rule

\begin{tabular}{|c|c|}
\hline No & Rule \\
\hline \multirow[t]{2}{*}{1} & IF GD01 $\boldsymbol{A N D}$ GD02 AND GD03 AND GD04 \\
\hline & AND GDO5 AND GD06 THEN PD01 \\
\hline \multirow[t]{2}{*}{2} & IF GD07 AND GD08 AND GD09 AND GD10 \\
\hline & THEN PD02 \\
\hline \multirow[t]{3}{*}{3} & IF GD01 AND GD11 AND GD12 AND GD13 \\
\hline & AND GD14 AND GD15 AND GD16 THEN \\
\hline & PD03 \\
\hline \multirow[t]{2}{*}{4} & IF GD17 AND GD18 AND GD19 AND GD20 \\
\hline & AND GD21 THEN PD04 \\
\hline \multirow[t]{3}{*}{5} & IF GD01 $\boldsymbol{A N D}$ GD22 AND GD23 AND GD24 \\
\hline & $A N D$ GD05 AND GD25 AND GD26 AND \\
\hline & GD27 AND GD28 THEN PD05 \\
\hline \multirow[t]{2}{*}{6} & IF GD29 AND GD30 AND GD31 AND GD32 \\
\hline & AND GD33 AND GD34 THEN PD06 \\
\hline \multirow[t]{3}{*}{7} & IF GD01 $\boldsymbol{A N D}$ GD23 AND GD24 AND GD05 \\
\hline & $A N D$ GD25 AND GD27 AND GD28 AND \\
\hline & GD35 AND GD36 THEN PD07 \\
\hline \multirow[t]{2}{*}{8} & IF GD37 $\boldsymbol{A N D}$ GD38 $\boldsymbol{A N D}$ GD39 $\boldsymbol{A N D}$ GD 40 \\
\hline & THEN PD08 \\
\hline
\end{tabular}

Setelah rule ditentukan maka akan dilakukan pengujian terhadap rule tersebut.

Contoh kasus :

Seorang pasien bernisial A mengunjungi klinik X untuk mendapatkan perawatan . pasien tersebut mengeluhkan adanya bintik putih pada mulutnya 
(GD30), di dalam mulutnya seperti ada kapas (GD33). Pada sudut mulut terdapat pecah-pecah dan kemerahan (GD29), lesinya menyerupai keju (GD32) dan ada pendarahan apabila lesi tersebut tergores (GD31). Dan pasien tersebut kehilangan nafsu makannya(GD34).

Dari gejala yang diderita pasien tersebut proses penelusuran menggunakan metode forward chaining adalah

Fakta : GD30, GD33, GD29, GD32, GD31, GD34

Goal : Diagnosa penyakit dari gejala-gejala yang dirasakan pasien

Proses penelusuran menggunakan metode forward chaining dapat dilihat pada Gambar 1

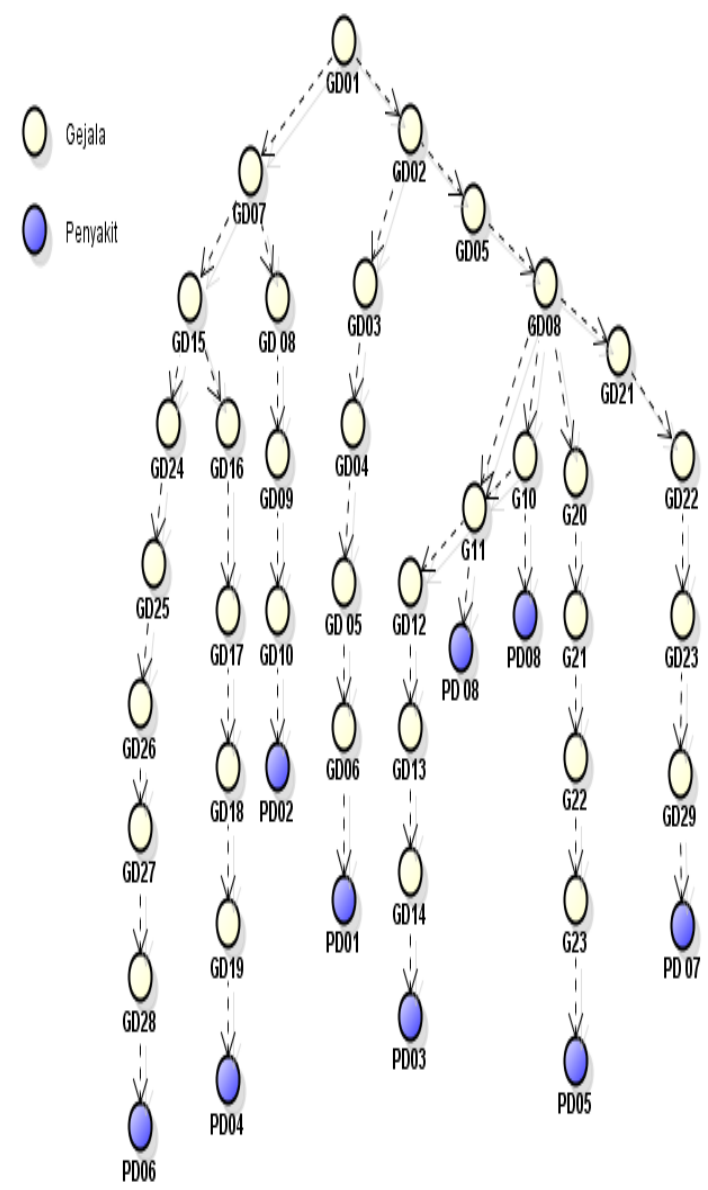

Gambar 1. Pohon Keputusan Diagnosa Penyakit Gigi dan Mulut

Sedangkan proses iterasi untuk contoh kasus dapat dilihat pada Gambar 2

Iterasi 1

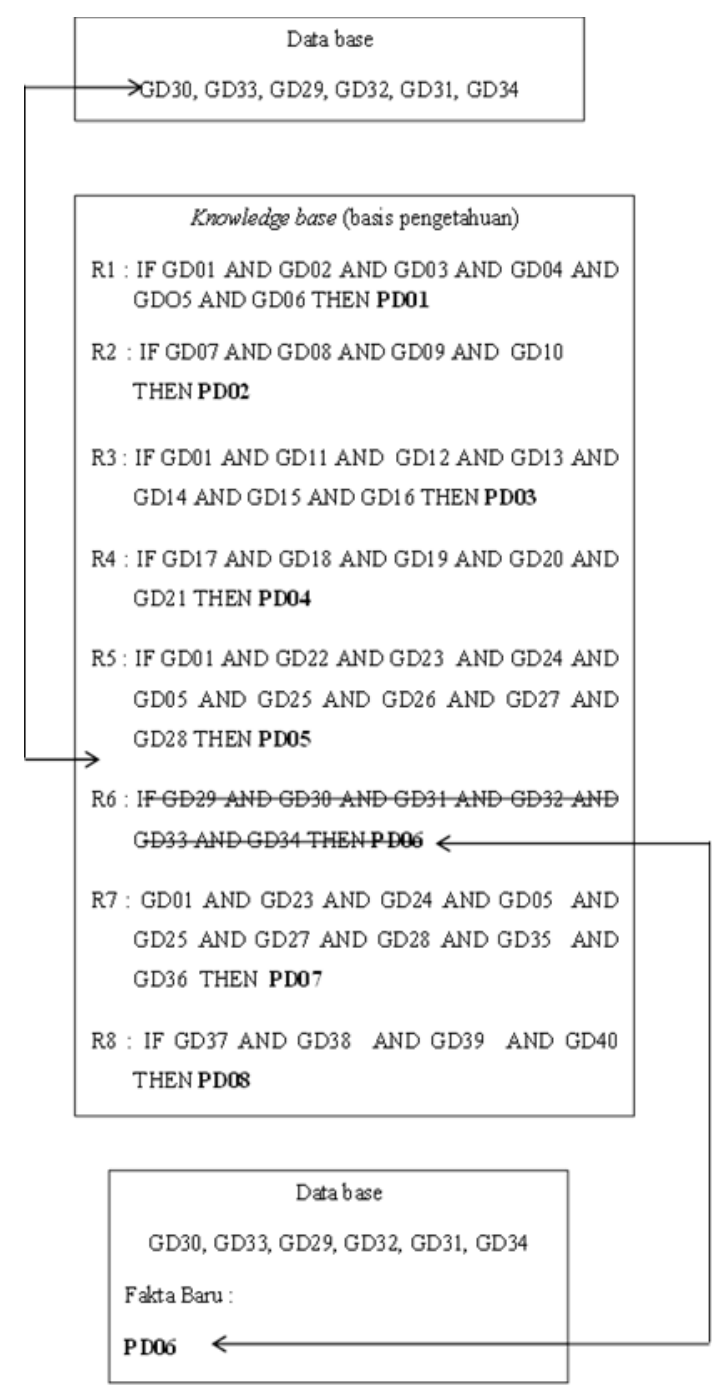

Gambar 2. Proses Pencarian Rule pada Metode Forward Chaining

Sampai disini proses akan dihentikan karena sudah tidak ada lagi data diri database yang menyebutkan untuk mengeksekusi rule yangtelah ada maka, hasil pencarian PD01 bernilai benar. Maka dari hasil eksekusi tersebut penyakit yang terdeteksi adalah PD01 yaitu penyakit Gingivitis.

\section{Kesimpulan}

Kesimpulan yang didapatkan dari hasil penelitian yang telah dilakukan. Penerapan metode Forward Chaining dapat membantu dokter dalam melakukan diagnosa penyakit. Aplikasi sistem pakar dirancang dengan menggunakan metode forward chaining yang dapat membantu pengguna (user) untuk mendeteksi penyakit gigi dan mulut yang diderita serta solusi penanganannya.

\section{Daftar Pustaka}

[1] Arifin, Jaenal, 2016. Sistem Pakar Diagnosa Penyakit Gigi dan Mulut Manusia Menggunakan Knowledge Base System dan 
Certainty Factor, , Jurnal Ilmiah Teknologi dan Informatika ASIA (JITIKA), ISSN: 0852-730X

[2] Meyliana, Anastasia dkk, 2016. Sistem Pakar Pada Konsultasi Jenis Senam dengan Metode Forward Chaining, Jurnal INFORMA Politeknik Indonusa Surakarta Vol. 1 Nomor 3, ISSN : 2442-7942

[3] Nur, Febi Salihah dkk, 2015. Sistem Pakar Penentuan Bakat Anak dengan Menggunakan Metode Forward Chaining, Jurnal Rekayasa dan Manajemen Sistem Informasi Vol, Nomor 1 , ISSN 2460-8181

[4] Astuti, Indryani dkk, 2017. The Expert System of Children's Digestive Tract Diseases Diagnostic using Combination of Forward Chaining and Certainty Factor Methods, International Conference on Science in Information Technology (ICSITech), 978-15090-5864-8/17/\$31.00 @2017 IEEE

[5] Nugraha, Eka Yakub dkk, 2017. System Design and Implementation Automation System of Expert System on Hydroponics Nutrients Control using Forward Chaining, IEEE Asia Pacific Conference on Wireless and Mobile
(APWIMob), 978-1-5386-2373-2/17/\$31.00 (C)2017 IEEE

[6] Putri, Anggia Dasa dan Dedy Suhendra, 2016. Sistem Pakar untuk Mendeteksi Kerusakan Air Conditioner Menggunakan Metode Forward Chaining Berbasis Web, Jurnal INOVTEK POLBENG Vol. 1, Nomor 2, ISSN: 2521-9866

[7] Verina, Wiwi, 2015. Penerapan Metode Forward Chaining untuk Mendeteksi Penyakit THT, Jatisi Vol. 1, Nomor 2, ISSN:2407-4322

[8] Maharani, Septya dkk, 2015. Expert System Applications for Early Diagnosis Teeth and Oral Disease in Children, Conference on Information Technology, Computer and Electrical Engineering (ICITACEE), 978-14799-9863-0/15/\$31.00 c2015 IEEE

[9] Raharjo, Joko S Dwi, 2016. Sistem Pakar Diagnosa Penyakit Lambung dengan Metode Forward Chaining berbasis Android, Jurnal SISFOTEK GLOBAL Vol. 6 Nomor 2, ISSN: 2088-1762 